\title{
Effect of etchant concentration and defects on pyramid formation in TMAH etched silicon
}

\author{
W K CHOI*, J T L THONG, Y BAI, PUNEET NEWASKAR and P LUO \\ Microelectronics Laboratory, Department of Electrical Engineering, National University of Singapore, 10 Kent \\ Ridge Crescent, Singapore 119260
}

\begin{abstract}
An investigation on the effect of TMAH concentration on the etch rate of silicon, and the influence of etchant concentration, ambient temperature and wafer thermal history on the formation of pyramids at the surface of TMAH etched silicon has been carried out. From the results obtained from this study, we are able to explain the influence of TMAH concentration and ambient temperature on the silicon etch rate and the changes occurring at the silicon surface satisfactorily using the pH theory. However, the results from wafers with different thermal history seem to favour the defects theory. We suggest that in order to explain the etching mechanism of TMAH of silicon satisfactorily, a combination of $\mathrm{pH}$ and defects theories is necessary.
\end{abstract}

Keywords. Etching parameters; pyramids; silicon; tetramethylammonium hydroxide (TMAH).

\section{Introduction}

Anisotropic silicon etching is often required in the fabrication of microelectromechanical structures. Schnakenberg et al (1991) and Tabata et al (1992) developed a new etchant, tetramethylammonium hydroxide (TMAH, $\left(\mathrm{CH}_{3}\right)_{4} \mathrm{NOH}$ ), for the anisotropic etching of silicon. The advantages of TMAH as compared to other types of etchant such as $\mathrm{KOH}$, ethylenediaminepyrocatechol-water (EDP), or hydrozine-water solutions are that it is CMOS compatible and non-toxic. Recently, we have carried out a study on TMAH etching of silicon and examined the interaction of various etching parameters (Thong et al 1997).

In this paper, we investigate the effect of TMAH concentration on the etch rate of silicon. In these etching experiments, we found that the silicon surface condition is often related to etching conditions. Of particular interest is the formation of pyramids at the etched silicon surface. Therefore, we also aim to examine here the influence of TMAH concentration $\left(N_{c}\right)$, ambient temperature and wafer thermal history on the formation of pyramids at the surface of TMAH etched silicon.

\section{Experimental}

Three types of wafers were used in this work. Type I wafers were $n$-type Czochralski (CZ) silicon wafers with resistivities of $4-8 \Omega \mathrm{cm}$ and (100) orientation. Types II and III wafers were also $n$-type, (100) oriented CZ

*Author for correspondence wafers with resistivities of $5-10 \Omega \mathrm{cm}$. Types II and III wafers were used for the experiments described in $\$ 3.2 \mathrm{a}$. The passivation oxide layer was thermally grown to a thickness of $0.5 \mu \mathrm{m}$. Windows of $5 \times 5 \mathrm{~mm}^{2}$ were patterned in the oxide layer and later etched to provide openings for the etching exercise. Before immersing the samples in TMAH solution, they were dipped in $10 \%$ hydrofluoric acid for a few $\mathrm{sec}$ and then rinsed in deionized water. The sample was held horizontally throughout the etching process. All the etching experiments were carried out in a glass vessel with the TMAH temperature controlled by a temperature bath. A reflux condenser was used to prevent change in the TMAH etchant volume during etching. The etchants were prepared by dilution of commercially available TMAH solution with $N_{\mathrm{c}}=25 \mathrm{wt} \%$.

For the investigation of pyramid formation, the size $\left(N_{\mathrm{s}}\right)$ and the number $\left(N_{\mathrm{p}}\right)$ of the pyramids at the centre of the $5 \times 5 \mathrm{~mm}^{2}$ window were observed using a scanning electron microscope (Hitachi Model: S-4100). Note that the area that was covered by a single SEM examination is $30 \times 40 \mu \mathrm{m}^{2}$. A total of nine pictures (i.e. $10800 \mu \mathrm{m}^{2}$ ) was taken around the centre region of the window for all the experiments. The values of $N_{\mathrm{s}}$ and $N_{\mathrm{p}}$ were obtained from the SEM pictures using an image processing software (Scion). In using this software, a region of interest of $360 \times 420$ pixels was created on the SEM image. A comparison of different images can be made via the software by adjusting the 'threshold level'. For a particular threshold level, number of pyramids in a fixed size can then be obtained by measuring the total area of interest. 


\section{Results and discussion}

\subsection{Etch rate of silicon}

Figure 1 shows the etch rate of type $I$ wafers as a function of $N_{\mathrm{c}}$. The etch rate increases as $N_{\mathrm{c}}$ increases from 2 to $4 \mathrm{wt} \%$, and it reaches a maximum value of $67.62 \mu \mathrm{m} / \mathrm{h}$. Further increase in $N_{\mathrm{c}}$ to 6 and $15 \mathrm{wt} \%$ resulted in a slight decrease in the etch rate. Also shown in figure 1 are the etching results of Schnakenberg et al (1991) and Tabata et al (1992). Apart from the difference in the values of the etch rate, it can be seen from figure 1 that there is a general agreement in the variation in the etch rate as a function of TMAH concentration. The difference in the etch rates between that of Schnakenberg et al (1991), Tabata et al (1992) and the present work could be due to the difference in the substrate resistivity, as suggested by Bhatnagar and Nathan (1993).

\subsection{The pyramids}

During the etching experiments described in $\S 3.1$, it was found that the silicon surface can change from a very rough to a very smooth surface when etched with different $N_{\mathrm{c}}$. In this section, an investigation on pyramid formation as a function of $N_{\mathrm{c}}$, silicon etch depth, ambient temperature and silicon thermal history will be carried out.

Figure 2 shows the SEM pictures of two silicon surfaces etched with $N_{\mathrm{c}}=15 \mathrm{wt} \%$ for $30 \mathrm{~min}$ at $90^{\circ} \mathrm{C}$. Figure 2a shows the pyramids of different sizes bound by the $\langle 111\rangle$ surfaces. At some locations at the silicon surface, a number of pyramids appear to enmesh together with smaller pyramids arising out from the surfaces of a bigger pyramid. Figure $2 b$ shows the octagonal type of pyramids observed at the silicon surface of the same sample as figure 2a. Note that the majority of the pyramids reported in this work are of the octagonal type. The existence of the octagonal pyramids have also been reported by Lee (1969) and Matsuoka et al (1992). Our pyramids are substantially smaller than that reported by Schnakenberg et al (1990) and Bhatnagar and Nathan (1993), but are similar to that reported by Tabata et al (1992) and Matsuoka et al (1992).

3.2a Wafer types: Figure 3 shows the SEM pictures of types I, II and III silicon wafers when etched with $15 \mathrm{wt} \%$ TMAH for $30 \mathrm{~min}$. In this figure, type III wafer shows the smoothest surface among the three types of wafers, and type II has bigger pyramids than type I. As types I, II and III wafers were obtained from different suppliers, the wafer preparation conditions will definitely be different. Therefore, one can conclude that the existence of pyramids is very dependent on the wafer

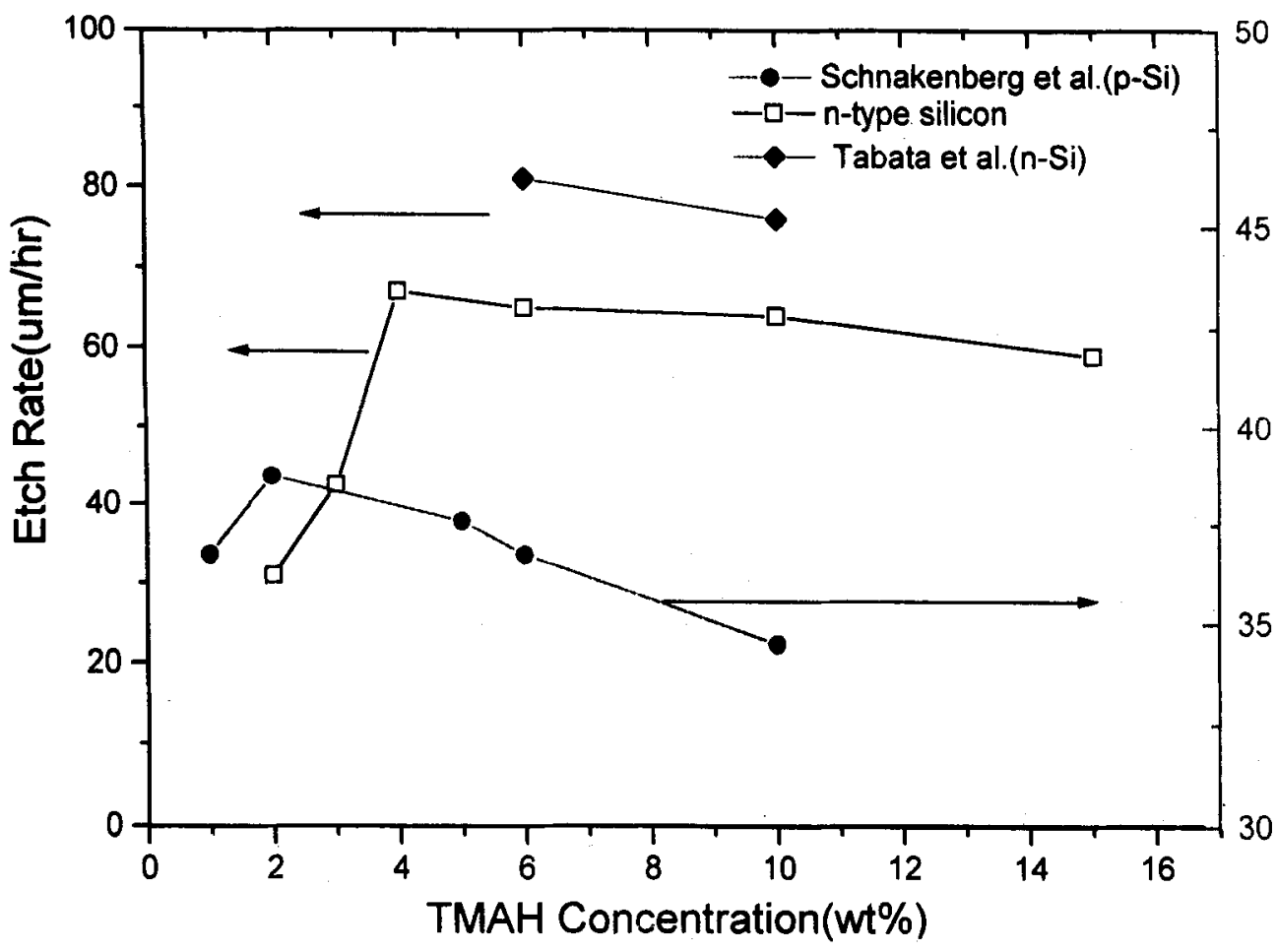

Figure 1. The silicon etch rate as a function of TMAH concentration. Note that data from Schnakenberg et al (1992) and Tabata et al (1992) have also been included for comparison. 
preparation history. Further investigation on the effect of wafer history on the formation of pyramids will be presented in $\$ 3.2 \mathrm{e}$.

3.2b Pyramids at different etch depths: In this section, three type I silicon wafers were etched to a depth of $2,9,21 \mu \mathrm{m}$, respectively. The $N_{\mathrm{s}}$ and $N_{\mathrm{p}}$ values of these samples are plotted in figure 4 . It can be seen from this figure that no significant difference in the values of $N_{\mathrm{s}}$ and $N_{\mathrm{p}}$ can be found when the silicon was etched to different depths. This means that the pyramids must 'appear' and 'disappear' at the silicon surface as etching progresses. This is in agreement with the suggestion of Bhatnagar and Nathan (1993). Also note that as $N_{\mathrm{s}}$ and $N_{\mathrm{p}}$ are independent of the etch depth, all the subsequent etching experiments were performed with the etching time fixed at $30 \mathrm{~min}$.
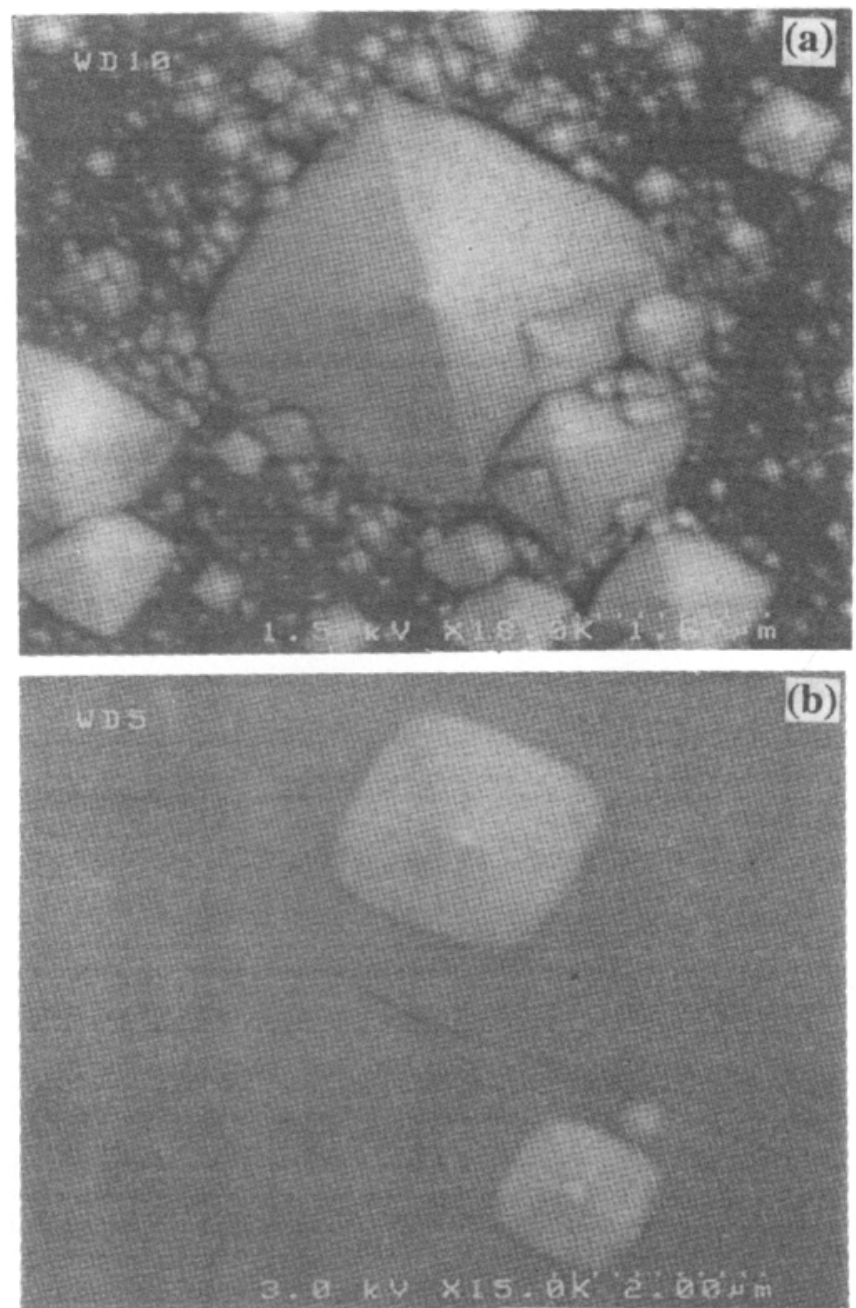

Figure 2. SEM pictures of the silicon surface etched with $15 \mathrm{wt} \% \mathrm{TMAH}$ for $30 \mathrm{~min}$ at $90^{\circ} \mathrm{C}$. Note that (a) shows the pyramids with square base and (b) shows the octagonal base pyramids. 3.2c Influence of $N_{c}:$ Figure 5 shows the SEM pictures of the silicon surface when etched with different $N_{\mathrm{c}}$. In figure 5 a a very rough surface is obtained when etched with $N_{\mathrm{c}}=10 \mathrm{wt} \%$. The roughness of the surface reduces significantly when etched with $N_{\mathrm{c}}=12 \mathrm{wt} \%$ (see figure $5 b$ ). The roughened portions of the silicon surface are irregular in shape and size. Pyramids can only be observed in figure $5 \mathrm{c}$ where the silicon was etched with $N_{\mathrm{c}}=15 \mathrm{wt} \%$. The number and size of pyramids reduce significantly when $N_{\mathrm{c}}$ increases from 15 to $20 \mathrm{wt} \%$.
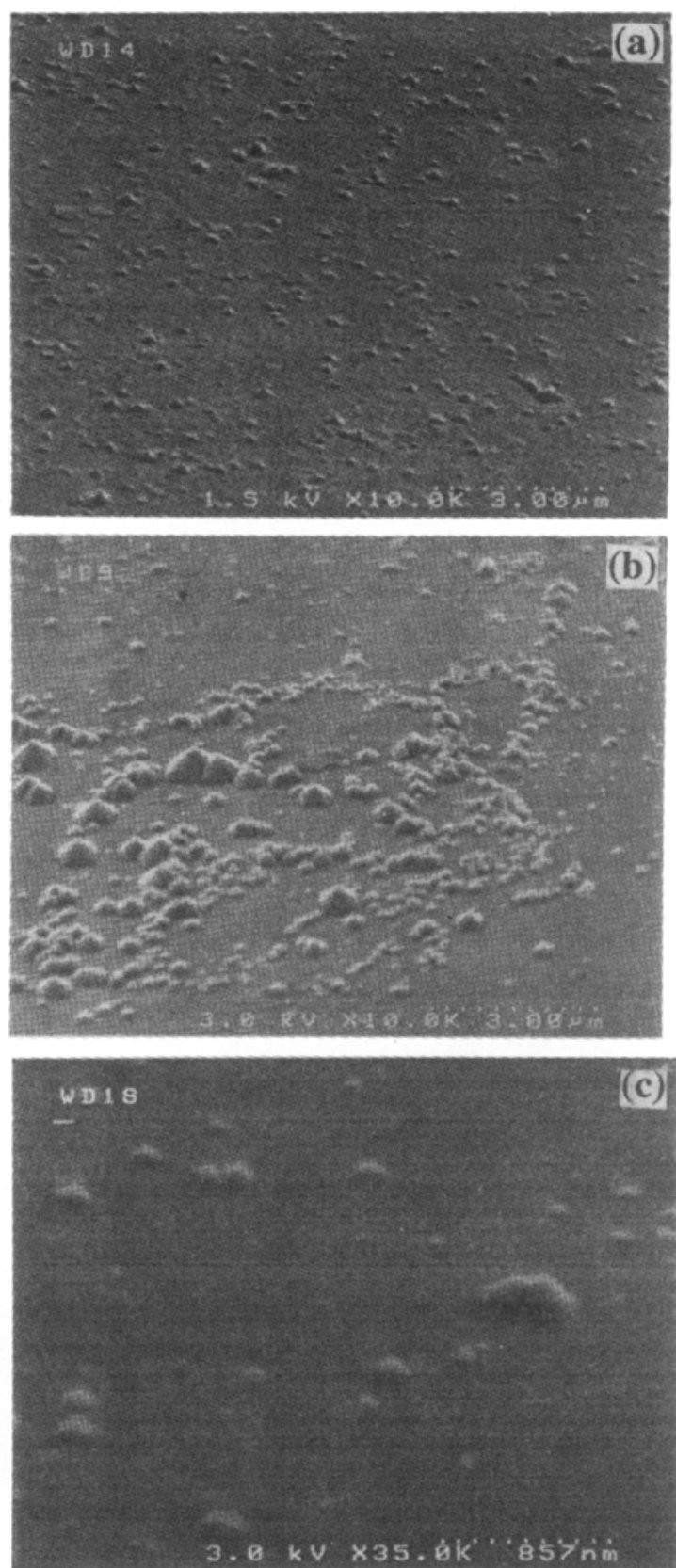

Figure 3. SEM pictures of the silicon surface of (a) type I, (b) type II and (c) type III wafers etched with $15 \mathrm{wt} \%$ TMAH at $90^{\circ} \mathrm{C}$ for $30 \mathrm{~min}$ observed at $60^{\circ}$ tilt. 
Figure 6 plots $N_{\mathrm{p}}$ versus $N_{\mathrm{s}}$ for $N_{\mathrm{c}}=15$ and $20 \mathrm{wt} \%$. It can be seen from this figure that at $N_{\mathrm{c}}=15 \mathrm{wt} \%$, approximately 227 pyramids are less than $0.1 \mu^{2} . N_{\mathrm{p}}$ drops drastically to around 47 for $0.1 \mu \mathrm{m}^{2}<N_{\mathrm{s}}<0.2 \mu \mathrm{m}^{2}$. A similar trend can also be observed for the pyramids when etched with $20 \mathrm{wt} \%$ TMAH. Noted that, however, $N_{\mathrm{p}}$ reduces significantly from 227 to 42 for $N_{\mathrm{s}}<0.1 \mu \mathrm{m}^{2}$ when $N_{\mathrm{c}}$ is increased from 15 to $20 \mathrm{wt} \%$.

A model for the etching of silicon that consists of a series of oxidation and chelation processes has been proposed by Schnakenberg et al $(1990,1991)$. In this model, the silicon surface is first oxidized and then chelated to form a product which can be dissolved away. The oxidation process can be expressed as:

$$
\begin{aligned}
& \mathrm{Si}+2 \mathrm{OH}^{-} \rightarrow \mathrm{Si}(\mathrm{OH})_{2}^{++}+4 \mathrm{e}^{-} \\
& \mathrm{Si}(\mathrm{OH})_{2}^{++}+4 \mathrm{OH}^{-} \rightarrow \mathrm{SiO}_{2}(\mathrm{OH})_{2}^{--}+2 \mathrm{H}_{2} \mathrm{O}
\end{aligned}
$$

and the chelation process as

$$
4 \mathrm{H}_{2} \mathrm{O}+4 \mathrm{e}^{-} \rightarrow 4 \mathrm{OH}^{-}+2 \mathrm{H}_{2} .
$$

The overall reaction can be summarized as (Seidel et al 1991)

$$
\mathrm{Si}+2 \mathrm{OH}^{-}+2 \mathrm{H}_{2} \mathrm{O} \rightarrow \mathrm{SiO}_{2}(\mathrm{OH})_{2}^{--}+2 \mathrm{H}_{2} .
$$

As $N_{\mathrm{c}}$ changes from one comprising mainly the oxidizing agent to one comprising mainly the chelation agent, the etch rate should go through a maximum such that the oxidation and chelation processes are most efficient. From the results presented in $\S 3.1$, the oxidation and chelation processes are most efficient at $N_{\mathrm{c}}=4 \mathrm{wt} \%$. As $N_{\mathrm{c}}$ is increased from 2 to $4 \mathrm{wt} \%$, the oxidation reaction dominates and silicon is removed rapidly. This resulted in the sharp increase in the etch rate. It also means that at the silicon surface, the number of $\mathrm{SiO}_{2}(\mathrm{OH})_{2}^{--}$would also increase.

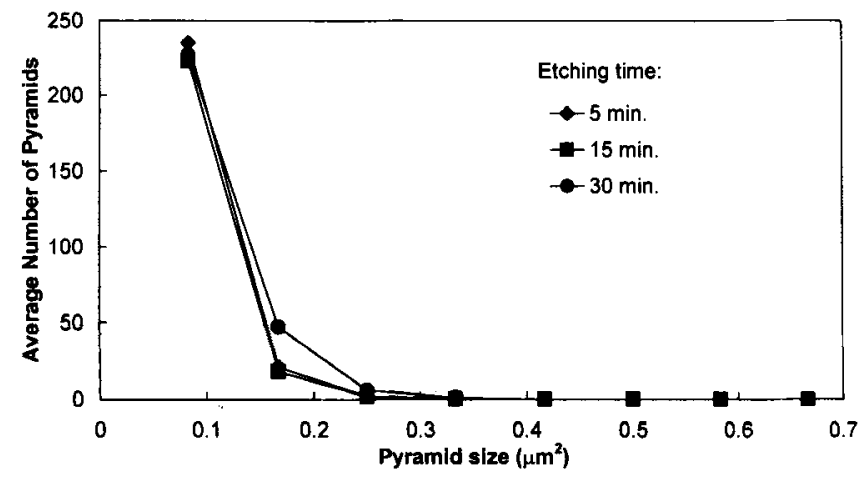

Figure 4. The number $\left(N_{\mathrm{p}}\right)$ and size $\left(N_{\mathrm{s}}\right)$ of the pyramids as a function of the silicon etch depth. The silicon wafers were etched with $15 \mathrm{wt} \% \mathrm{TMAH}$ at $90^{\circ} \mathrm{C}$ for 5,15 and $30 \mathrm{~min}$.
It has been suggested that the pyramids originate when $\mathrm{SiO}_{2}(\mathrm{OH})_{2}^{--}$fails to be dissolved away in the etching solution (Schnakenberg et al 1990). The accumulation of $\mathrm{SiO}_{2}(\mathrm{OH})_{2}^{--}$may account for the very rough silicon surface. This suggestion is reasonable as Finne and Klein (1967), Wu and Ho (1989) and Reishman et al (1979) have all observed surface pitting and the formation of residue at the silicon surface when etched with EDP or
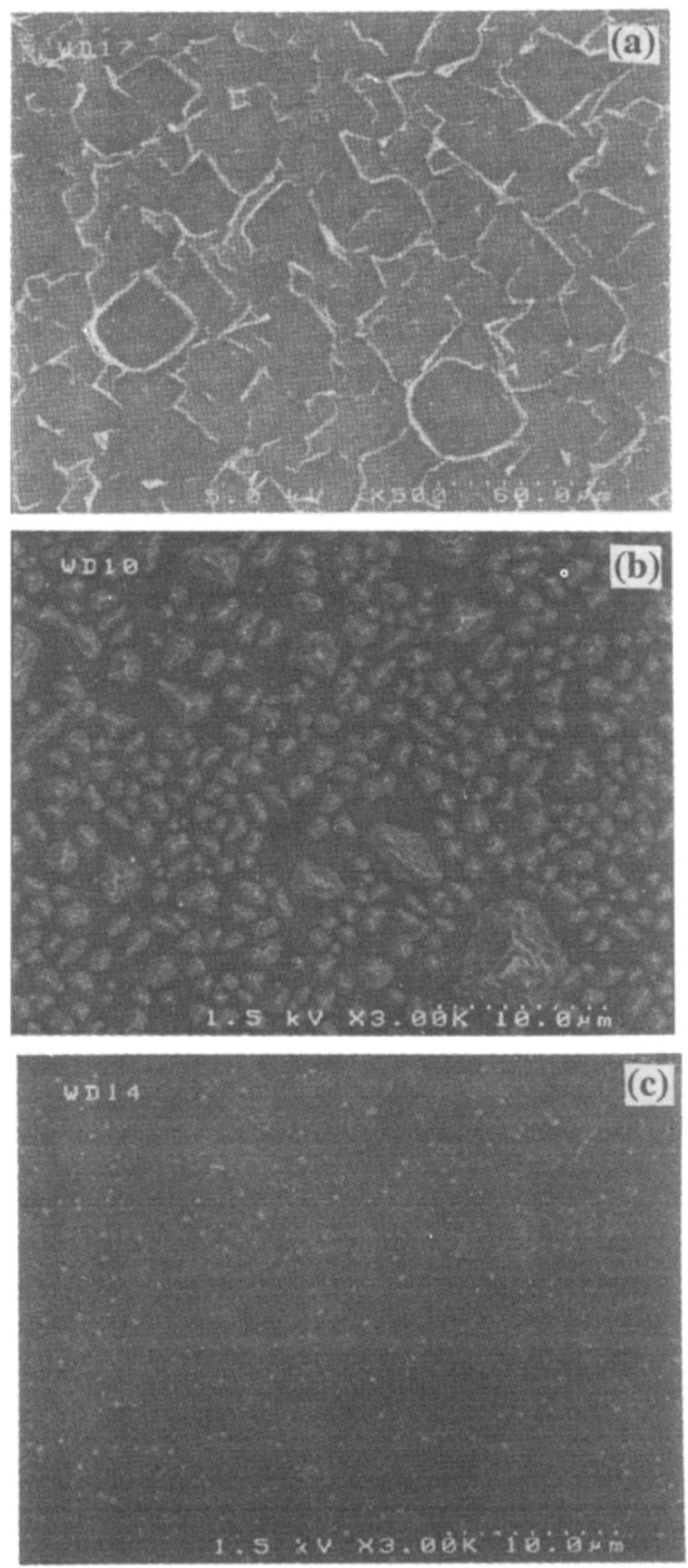

Figure 5. SEM pictures of the silicon surface etched with different TMAH concentrations at $90^{\circ} \mathrm{C}$ for $30 \mathrm{~min}$. Note that (a) $N_{\mathrm{c}}=10 \mathrm{wt} \%$, (b) $N_{\mathrm{c}}=12 \mathrm{wt} \%$ and (c) $N_{\mathrm{c}}=15 \mathrm{wt} \%$. 
hydrazine. The residue was determined to be mostly composed of $\mathrm{SiO}_{2}$. We further suggest that as $N_{\mathrm{c}}$ is increased from 4 to $12 \mathrm{wt} \%$, even though the chelation process is becoming increasingly dominant, the removal of $\mathrm{SiO}_{2}(\mathrm{OH})_{2}^{--}$is still not too significant as the silicon surface is still fairly rough (see figure 5). When $N_{\mathrm{c}}>12$ wt\%, the removal of $\mathrm{SiO}_{2}(\mathrm{OH})_{2}^{--}$becomes significant and the silicon surface would become smoother. As $N_{c}$. increases to 15 and $20 \mathrm{wt} \%$, one would expect a further reduction in $\mathrm{SiO}_{2}(\mathrm{OH})_{2}^{--}$. This is in very good agreement with the results shown in figure 6 in that the number of pyramids reduces from 225 to 40 as $N_{\mathrm{c}}$ is increased from 15 to $20 \mathrm{wt} \%$.

Note that our proposal is also similar to that of Gadja and Ahmed (1994). Gadja and Ahmed proposed that the nature of the etching mechanism is a competition between the rate of dissolution of silicon and the passivation of

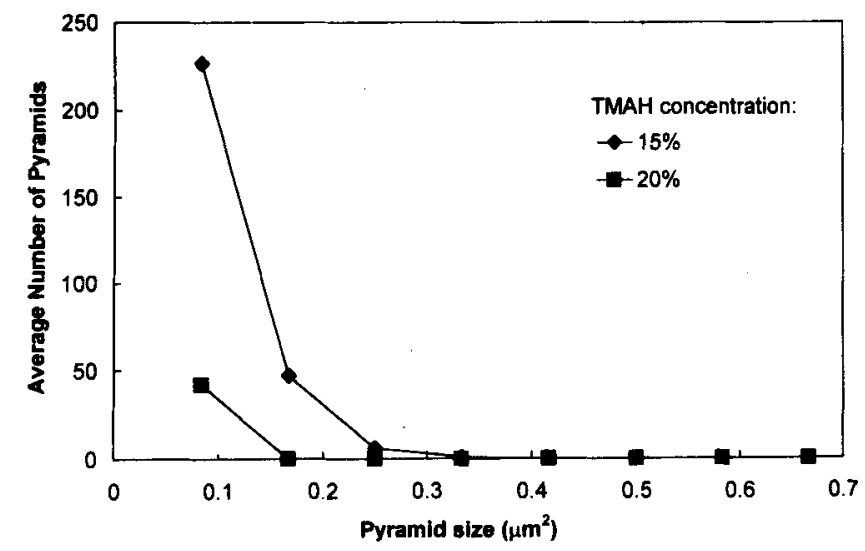

Figure 6. Number $\left(N_{\mathrm{p}}\right)$ vs size $\left(N_{\mathrm{s}}\right)$ of the pyramids plots for $N_{\mathrm{c}}=15$ and $20 \mathrm{wt} \%$. The etching temperature was $90^{\circ} \mathrm{C}$ and etching time $30 \mathrm{~min}$.

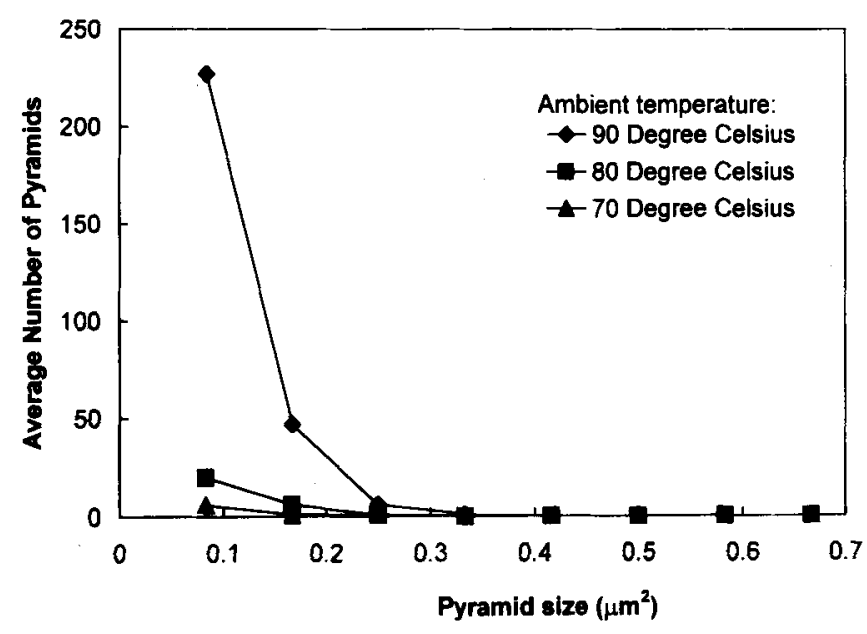

Figure 7. $N_{\mathrm{p}}$ vs $N_{\mathrm{s}}$ plots for the wafers etched with $N_{\mathrm{c}}=15$ wt\% for $30 \mathrm{~min}$ at (a) $70^{\circ} \mathrm{C}$, (b) $80^{\circ} \mathrm{C}$ and (c) $90^{\circ} \mathrm{C}$. the surface by the accumulation of the reaction product. They suggested that when the concentration of $\mathrm{OH}^{-}$ increases, the silicon surface becomes smoother.

3.2d Ambient temperature: Figure 7 shows the $N_{\mathrm{p}}$ vs $N_{\mathrm{s}}$ plot for TMAH etching experiments with $N_{\mathrm{c}}=15 \mathrm{wt} \%$ and $T=70,80$ and $90^{\circ} \mathrm{C}$ for $30 \mathrm{~min}$. The number of
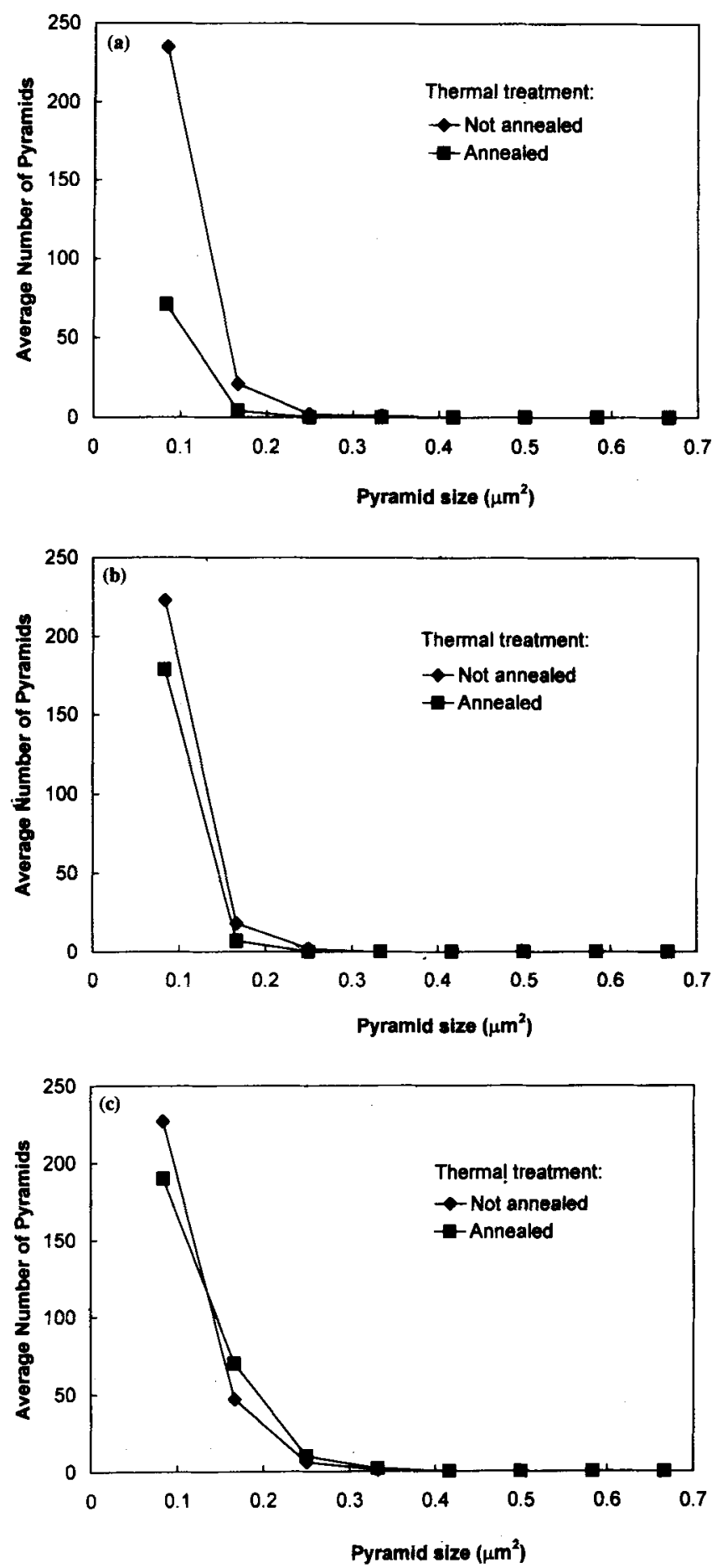

Figure 8. $N_{\mathrm{p}}$ vs $N_{\mathrm{s}}$ plots for the rapid thermal annealed and as-received silicon wafers etched with $N_{\mathrm{c}}=15 \mathrm{wt} \%$ at $90^{\circ} \mathrm{C}$ for (a) $5 \mathrm{~min}$, (b) $15 \mathrm{~min}$ and (c) $30 \mathrm{~min}$. 
pyramids $\left(N_{s}<0.1 \mu \mathrm{m}^{2}\right)$ increases significantly from 6 to 227 as the ambient temperature increases from 70 to $90^{\circ} \mathrm{C}$. The silicon etch rate also increases from 18 to $49 \mu \mathrm{m} / \mathrm{h}$ as the ambient temperature increases from 70 to $90^{\circ} \mathrm{C}$. This means that reaction (4) becomes more active as the ambient temperature increases. This would increase the number of $\mathrm{SiO}_{2}(\mathrm{OH})_{2}^{--}$and thus the number of pyramids.

3.2e Annealing: A silicon wafer was rapid thermal annealed in argon at $900^{\circ} \mathrm{C}$ for $50 \mathrm{sec}$ prior to the opening of the oxide window for etching. The samples were subsequently etched for 5,15 and $30 \mathrm{~min}$. The $N_{\mathrm{p}}$ vs $N_{\mathrm{s}}$ plots for the different etching times are shown in figure 8 . Note that in figure 8 , an as-received silicon wafer etched under exactly the same conditions as the RTA wafer, is included for comparison.

It can be seen from figure $8 \mathrm{a}$ that when etched for $5 \mathrm{~min}$, there is a distinct difference in $N_{\mathrm{p}}$ between the RTA and the un-annealed samples. $N_{\mathrm{p}}$ in the as-received and RTA samples are about 235 and 70 , respectively. This difference in $N_{\mathrm{p}}$ becomes smaller (see figure $8 \mathrm{~b}$ ) when the RTA and the as-received samples were etched for $15 \mathrm{~min}$. Figure $8 \mathrm{c}$ shows that the difference in $N_{\mathrm{p}}$ becomes indistinguishable when the samples were etched for $30 \mathrm{~min}$.

We have reported that rapid thermal annealing silicon wafer at $900^{\circ} \mathrm{C}$ will cause the interstitial oxygen atoms $\left(\mathrm{O}_{\mathrm{i}}\right)$ to outdiffuse from the silicon bulk (Choi et al 1995). We suggest that the difference in the $N_{\mathrm{p}}$ values between the RTA and the as-received samples is due to the difference in $O_{i}$ of these samples. It means that $O_{i}$ also influences the formation of the pyramids. As the annealing time was relatively short, one would expect only $\mathrm{O}_{i}$ close to the silicon-silicon oxide interface to be affected by RTA. Therefore, there should be no difference in the $O_{i}$ concentration deeper into the silicon between the RTA and as-received samples. Thus, one would not expect any difference in the number and/or size of the pyramids between the RTA and the as-received samples when etched for $30 \mathrm{~min}$. This agrees very well with the results shown in figure 8.

We have also etched a float zone (FZ) wafer with exactly the same etching conditions as that of figure 8 and found that the silicon surface is very smooth. We have to increase the magnification of the SEM to $20 \mathrm{kX}$ to locate the pyramids. The pyramids are generally much smaller and less dense than the $\mathrm{CZ}$ wafers used in this work. FZ wafers are known to contain significantly less $\mathrm{O}_{i}$ and the results of FZ wafer provides a strong support of our argument presented in the previous paragraph.

It is well known that $O_{i}$ in the $C Z$ wafers will be converted to thermal donors (TD) when the wafers are annealed in $\mathrm{N}_{2}$ at $450^{\circ} \mathrm{C}$ for $64 \mathrm{~h}$ (Choi et al 1995; Stein et al 1986). Figure 9 shows the $N_{\mathrm{p}}$ vs $N_{\mathrm{s}}$ results of a TD wafer and an as-received CZ wafer. It can be seen from this figure that $N_{\mathrm{p}}$ of the TD sample is generally higher than the as-prepared sample. As it has been suggested that the TD is related to $\mathrm{Si}_{x} \mathrm{O}_{y}$ complex (Stein et al 1986), it is clear from the results in figure 9

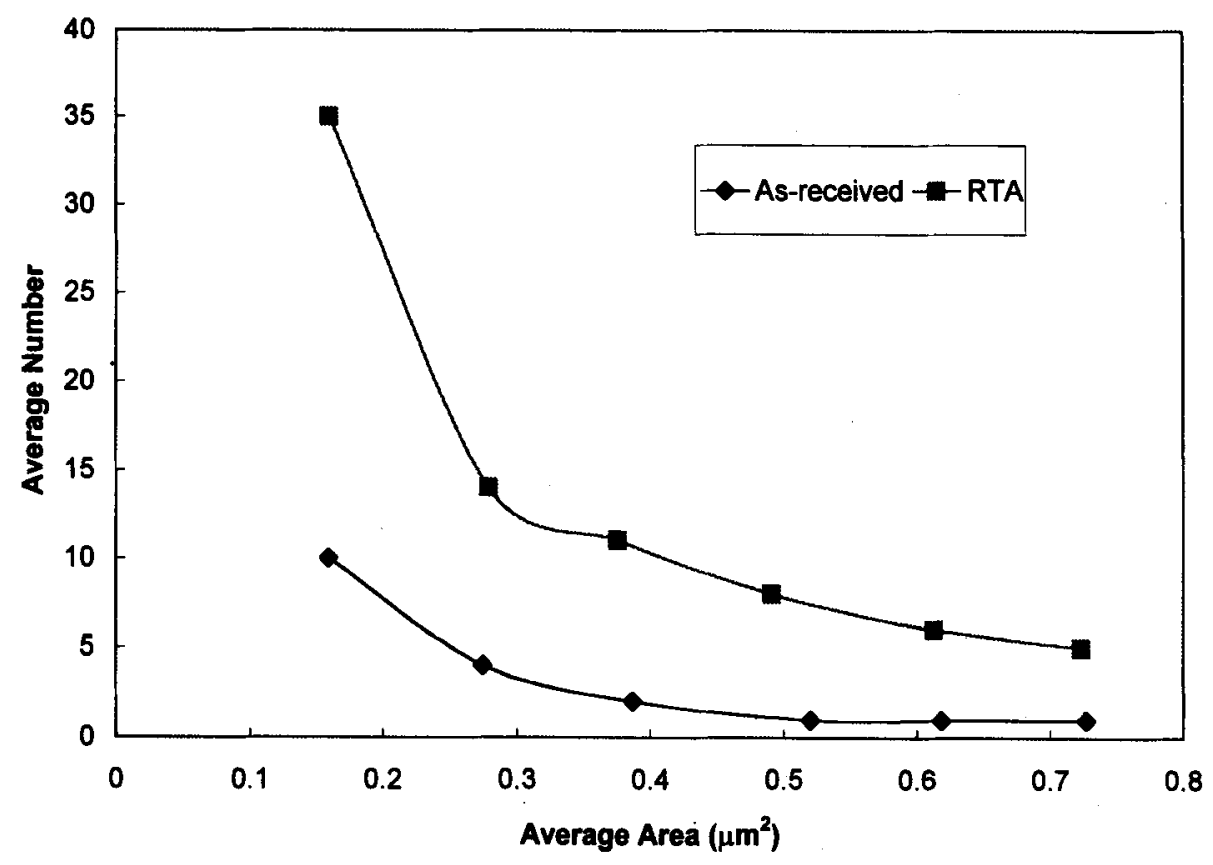

Figure 9. $N_{\mathrm{p}}$ vs $N_{\mathrm{s}}$ plots for the thermal donor created and as-received silicon wafers etched with $N_{\mathrm{c}}=15 \mathrm{wt} \%$ at $90^{\circ} \mathrm{C}$ for $30 \mathrm{~min}$. Note that the smaller number of $N_{\mathrm{p}}$ in this figure is due to the different wafers used. 
that the formation of pyramids is also related to $\mathrm{O}_{\mathrm{i}}$. It is perhaps worthwhile to note that Matsuoka et al (1992) had also proposed that the pyramids are caused by the silicon oxide precipitates within the silicon wafers. The silicon oxide precipitates have a slower dissolution rate than the bulk silicon and pyramids were formed with the silicon oxide precipitates located at the apex giving localized protection to the silicon underneath.

\section{Conclusion}

From the results presented in previous sections, we are able to explain the influence of TMAH concentration and ambient temperature on the density of pyramids satisfactorily using the $\mathrm{pH}$ theory of Schnakenberg et al (1990). However, the results of wafers with different thermal history seem to favour the defects theory of Matsuoka et al (1992). We suggest that in order to explain the etching mechanism of TMAH of silicon satisfactorily, a combination of $\mathrm{pH}$ and defects theories is necessary.

\section{Acknowledgements}

The authors wish to thank Mr Walter Lim and Mr K F Lee, Microelectronics Laboratory, Singapore, for their

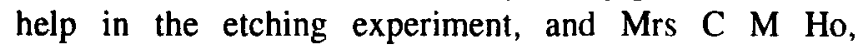
CICFAR, for her help in the SEM work. One of us (PN) would like to acknowledge the financial assistance provided by the California Institute of Technology under the SURF scheme. We would also like to thank the National Science and Technology Board for a RICUniversity Research Fund (No. 681301) and the National University for a Research Grant (No. 960607/A) for this work.

\section{References}

Bhatnagar Y K and Nathan A 1993 Sensors \& Actuators A36 233

Choi W K, Chan Y M, Ah L K, Loh F C, Tan K L and Raman A 1995 J. Appl. Phys. 784390

Finne R M and Klein D L 1967 J. Electrochem. Soc. 144965

Gadja M A and Ahmed H 1994 Sensors \& Actuators A40 227

Lee D B 1969 J. Appl. Phys. 404569

Matsuoka M, Yoshida Y and Monoruki M 1992 J. Chem. Eng. Jap. 25735

Reisman A, Berkenbilt M, Chan S A, Kaufman F B and Green D C 1979 J. Electrochem. Soc. 1261406

Schnakenberg U, Benecke W and Lochel B 1990 Sensors \& Actuators A21-23 1031

Schnakenberg U, Benecke W, Lochel B, Ullerich S and Lange P 1991 Sensors \& Actuators A25-27 1

Seidel H, Csepregi L, Heuberger A and Baumgartel H $1991 \mathrm{~J}$. Electrochem. Soc, 1373612

Stein H J, Hahn S K and Shatas S C 1986 J. Appl. Phys. 59 3495

Tabata O, Asahi R, Funabashi H and Sugiyama S 1992 Sensors \& Actuators A37-38 737

Thong J T L, Choi W K and Chong C W 1997 Sensors \& Actuators A63 243

Wu X and Ho W H 1989 Sensors \& Actuators 18207 